\title{
ENTOMOLOGY
}

\section{Biology and life table parameters of Metaphycus marensis Chirinos \& Kondo, 2019, an encyrtid parasitoid of guava cottony scale in Venezuela}

\author{
D.T. Chirinos, ${ }^{1}$ R. Castro, ${ }^{2}$ J. Castro, ${ }^{1}$ I. Perez-Almeida, ${ }^{3}$ T. Kondo ${ }^{4}$ \\ ${ }^{1}$ Facultad de Ingeniería Agronómica, Universidad Técnica de Manabí, Ecuador, ${ }^{2}$ Independent Research, Guayaquil, \\ Ecuador; ${ }^{3}$ Carrera de Ingeniería Agrónoma, Facultad de Ingenierías, Universidad ECOTEC, Ecuador; ${ }^{4}$ Corporación \\ Colombiana de Investigación Agropecuaria (AGROSAVIA), Colombia
}

\begin{abstract}
The guava cottony scale, Capulinia linarosae (Hemiptera: Eriococcidae) is an important pest of guava, Psidium guajava, in Venezuela and northern Colombia. Metaphycus marensis (Hymenoptera: Encyrtidae) is a new primary parasitoid species
\end{abstract}

Correspondence: Dorys T. Chirinos, Facultad de Ingeniería Agronómica, Universidad Técnica de Manabí, Portoviejo, 130105, Manabí, Ecuador. Tel.: +593.05.2632677

E-mail: dorysch66@gmail.com

Key words: Biological control, guava cottony scale, Metaphycus species, South America.

Acknowledgements: The authors would like to thank to the research project entitled "Identification of the main pests, natural enemies and viruses in some important crops in Ecuador and Venezuela" for the academic support given to this research. Many thanks to Dr Penny J. Gullan (The Australian National University, Canberra, Australia) for checking the English text and for useful comments of an earlier version of the text. Thanks also to anonymous reviewers for their useful comments that greatly helped improve the manuscript.

Contributions: DTC, substantial contributions to the conception or design of the work, analysis and interpretation of data forth work; RC, JC, IPA, TK, drafting the work or revising it critically for important intellectual content; final approval of the version to be published.

Conflict of interests: The authors declare no potential conflict of interests.

Funding: None

Received for publication: 9 January 2020.

Revision received: 25 March 2020.

Accepted for publication: 24 April 2020.

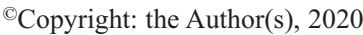

Licensee PAGEPress, Italy

Journal of Entomological and Acarological Research 2020; 52:8810 doi:10.4081/jear.2020.8810

This article is distributed under the terms of the Creative Commons Attribution Noncommercial License (by-nc 4.0) which permits any noncommercial use, distribution, and reproduction in any medium, provided the original author(s) and source are credited. recently described associated with this pest. Studies were conducted on oogenesis, life cycle, survival, daily fecundity and life table parameters of Metaphycus marensis Chirinos \& Kondo (Hymenoptera: Encyrtidae): intrinsic rate of natural increase $\left(r_{m}\right)$, generation time $(T)$ and net reproductive rate $\left(R_{o}\right)$. Females of $M$. marensis are synovigenic and this parasitoid goes through four larval instars and completes its life cycle in about 12.7 days. Survival was of type I, where mortality was initially detected by encapsulation of eggs and larvae. Metaphycus marensis was able to multiply its population 28.7 times $\left(R_{o}\right)$ with $r_{m}$ of 0.242 in 13.9 days $(T)$. The short generation time of the parasitoid in relation to its eriococcid host could represent a desirable attribute as a natural enemy. However, the low fecundity and the encapsulation by the host must be analyzed through field experiments in order to evaluate its effectiveness as a biological control agent for $C$. linarosae.

\section{Introduction}

Guava, Psidium guajava L. (Myrtaceae) is a crop native to the Americas and is currently distributed in tropical regions of the world, with a production of approximately 1.2 million MT, where India and Pakistan contribute $50 \%$ of the production worldwide, followed by Mexico (25\%) and the rest is produced by other countries, including Brazil, Colombia and Venezuela (Yam et al., 2010). Guava fruit is consumed both fresh and processed and it has a high potential as a commercial crop that derives from its uses, e.g., juices, nectars and pulps (Yam et al., 2010). The guava plant may be attacked and damaged by a wide range of insect pests, including, among others, scale insects. Within the latter, the most economically important insect species causing substantial crop losses worldwide belong to the families Pseudococcidae (mealybugs), Coccidae (soft scales) and Diaspididae (armored scales) (Miller et al., 2002; Gullan \& Cook, 2007; Mansour et al., 2017); and some species of Eriococcidae (Garcia Morales et al., 2020).

The family Eriococcidae (Hemiptera: Sternorrhyncha: Coccomorpha), the so called felt scales, is one of the four most species-rich scale insect families; these are phytophagous insects that feed on plant sap through their stylets and can infest one or several plant parts, e.g., fruits, leaves, main stems, roots or trunk (Miller, 2005). The Eriococcidae is most abundant in the southern hemisphere, where South America has a rich eriococcid fauna with 72 species in 24 genera (Hodgson et al., 2013).

Within the Eriococcidae, the cottony guava scale, Capulinia 
linarosae Kondo \& Gullan, 2017, is the most important pest insect of guava crop in Venezuela and the Caribbean coast of Colombia, a pest that causes severe damage to branches, leaves and fruits (Chirinos et al., 2017). The importance of this scale insect as a major guava pest has been documented for Venezuela (Chirinos et al., 2017) and more recently for the Caribbean coast of Colombia (Kondo et al., 2016).

Capulinia linarosae was first reported as a pest in Venezuela in 1993, devastating 600 hectares of guava cultivated areas in the Lake Maracaibo basin, the most important guava producing region in the country at that time (Chirinos et al., 2017). Biological studies showed that each female is capable of laying 2400 eggs, which gives it a high biotic potential and explains the high populations reached during colonization of the guava crop in the absence of efficient and effective natural enemies (Chirinos et al., 2017). This insect pest was reported recently in Colombia, where it causes considerable losses to guava in the Caribbean coast, involving both commercial crops and scattered backyard guava trees in the departments of Atlántico, Bolívar, Casanare, Cesar, Magdalena, Meta and Norte de Santander (Kondo et al., 2016; Ramos, 2018, Chirinos \& Kondo, 2019).

Metaphycus marensis Chirinos \& Kondo, 2019 (Hymenoptera: Encyrtidae) is so far the only species of primary parasitoid associated with $C$. linarosae, which was recently described based on specimens from Venezuela (Chirinos \& Kondo, 2019). This parasitoid is one of the natural biological control agents of this pest for which there is limited information in the literature and its potential as a control agent remains to be elucidated. Chirinos \& Kondo (2019) pointed out that M. marensis is an arrhenotokous species and the females prefer to parasitize young adult hosts.

Species of the genus Metaphycus play an important role in the natural regulation of their insect hosts and many species have been successfully used in biological control programs against agricultural pests, especially in soft scales of the genera Saissetia and Coccus (Guerrieri \& Noyes, 2000). Some 30 species of Metaphycus have been introduced to 40 countries for the control of approximately 22 species of scale insects (Guerrieri \& Noyes, 2000).

This paper presents novel biological information on $M$. marensis, which in addition to serving as a basis for insect breeding protocols, can be used to help understand the parasitoid-host ecological dynamics under field conditions and the potential of this parasitoid for managing C. linarosae in South America.

\section{Materials and Methods}

The study was carried out under controlled laboratory conditions (temperature: $26.7^{\circ} \mathrm{C}$; relative humidity $79.9 \%, 12: 12 \mathrm{~h}$ light/darkness) at University of Zulia, in Maracaibo, Venezuela. The culture conditions of the host and the parasitoid were as described in Chirinos \& Kondo (2019).

\section{Effect of feeding on oogenesis}

In our study, 60 mated female individuals of $M$. marensis, both unfed (30 individuals) and fed (30 individuals) with honey diluted in distilled water, were dissected 0, 24, 48, 72 and 96 hours after they emerged from the pupa. The total number of ovarioles was counted for each pair of ovaries. Also, the total number of eggs (i.e., fully developed and undeveloped eggs) was counted in both ovaries.

\section{Duration of the parasitoid life cycle}

To observe the development of the parasitoids, daily dissections of the eriococcid host were made. Twenty infested guava plants with young adult females of $C$. linarosae (11-15 days after molting) were exposed to two virgin or mated female parasitoids for 24 hours. During the first four days, dissections were done every 12 hours and afterwards every 24 hours from the fifth day until the end of the cycle. In each observation, five to seven eriococcid individuals were dissected per plant, which resulted in the evaluation of 10 to 15 parasitoids. When all the parasitoids reached the pupal stage, the parasitized eriococcid hosts were removed from the plant and placed in clear gelatin capsules until the emergence of the adult parasitoids.

Some of the parasitized hosts were dissected daily to observe the sclerotization of the parasitoid pupae. Some of the parasitoid eggs, larvae and pupae were mounted on slides using Hoyer's slidemounting medium following the method of Anderson (1954) in order to measure their greatest length and width. In the case of larvae, the width of the cephalic capsule and the length of the mandibles were also measured to determine the number of larval stages. Measurements were taken using image analysis software, Image-Pro Plus 6.0, Media Cybernetics ${ }^{\circledR}$.

\section{Parasitoid daily fecundity}

Fifty mated female parasitoids were released inside a cage containing plants with cultures of $C$. linarosae in order to count the daily number of eggs laid on the eriococcids. Thus, each guava plant with eriococcid hosts (about 200 females) was changed every 24 hours. This was repeated until the death of the female. When the female parasitoid was removed from each plant, all the eriococcid individuals found on the plant were dissected daily and the number of eggs laid was counted for each parasitized individual.

\section{Parasitoid survival $\left(\mathbf{l}_{\mathbf{x}}\right)$}

Each of 12 plants with 15 females of $C$. linarosae were exposed for 24 hours to two previously mated females of $M$. marensis. The observations took place every 12 hours post-exposure for the first four days and were subsequently made every 24 hours until the end of the cycle. Causes of mortality of M. marensis that were taken into account included the encapsulation of eggs and larvae, immobility and necrosis of larvae and drying of pupae. Observations were made every day on about 15 parasitoids that were obtained from dissections of the scales, counting the number of live parasitoids among the total observed. The parasitoid life table parameters were calculated following the previously referred method (Krebs, 1978): Net reproductive rate $\left(R_{o}\right)$, Generation time $(T)$ and Intrinsic rate of natural increase $\left(r_{m}\right)$.

\section{Statistical analysis}

The variables were transformed with the square root function $\sqrt{x \text { ? }]}$ and analyzed through the General Linear Model, and means were separated using the Least Squares method (LSM, P <0.05). All the statistical analyses were done with the statistical program SAS (SAS Institute Inc. 2009).

\section{Results}

\section{Effect of feeding on oogenesis}

Although host-feeding by the female parasitoid wasp was not observed, M. marensis is a synovigenic species that needs to feed on sources of carbohydrates in order for her eggs to mature. In the dissection of the ovaries, it was observed that each ovary is composed of three ovarioles (Figure 1A). For non-fed females, dissections were made only up to 24 hours because these wasps generally failed to survive beyond that time. For honey-fed females, dissections were performed until 96 hours after the emergence of 
the adult, a time that allowed observation of the differential development of the eggs. For newly emerged adult females $(0$ hours), only 1.7 developed eggs were detected on average per female, a value that increased 14 times after 96 hours.

The total number of eggs was similar and independent $(\mathrm{P}<0.05)$ of the feeding condition (Table 1). No significant differences were observed $(\mathrm{P}<0.05)$ in the number of eggs between fed and unfed females. However, significant differences in the number of developed eggs over time were observed for honey-fed females $(\mathrm{P}<0.05)$.

\section{Duration of the different stages and life cycle}

\section{Egg}

In M. marensis, the eggs are stalked (Figure 1B) and measure $160 \pm 15 \mu \mathrm{m}$ long × $67 \pm 4 \mu \mathrm{m}$ wide, excluding the stalked, which measures $75 \pm 9 \mu \mathrm{m}$ in length. Eggs lack an aeroscopic plate which is inserted in the fatty body at the caudal part of the body of the host (Figure 1C). The eggs are not fixed internally and can be easily detached, leaving them free inside the hemocoel.

\section{Larva}

Larvae are of the encyrtiform type, pass through four larval instars and mandibles are evident in all instars (Figures 1D-G, Figure 2) as well as head capsule width (Table 2).

\section{First-instar larva}

Once it hatches, the first-instar larva moves freely inside the host's hemocoel. The first-instar larva (Figure 1D) tends to be spheroidal, each $183 \pm 7 \mu \mathrm{m}$ long x $165 \pm 30 \mu \mathrm{m}$ wide. This stadium lasted approximately 24 hours.

Table 1. Number of developed eggs counted in the ovaries of $M$. marensis over time in both unfed and honey-fed adult females.

\begin{tabular}{|c|c|c|c|c|c|c|}
\hline \multirow[b]{2}{*}{ Time (hours) } & \multicolumn{3}{|c|}{ Honey-fed females } & \multicolumn{3}{|c|}{ Unfed females } \\
\hline & Total number of eggs & Developed eggs & N. & Total number of eggs & Developed eggs & N. \\
\hline 0 & $41.0 \pm 0.9 \mathrm{a}$ & $1.7 \pm 0.1 \mathrm{a}$ & 30 & $42.0 \pm 0.4 \mathrm{a}$ & $1.6 \pm 0.7 \mathrm{a}$ & 30 \\
\hline 24 & $39.2 \pm 1.4 \mathrm{a}$ & $14.4 \pm 2.6 \mathrm{~b}$ & 30 & $41.4 \pm 0.9 \mathrm{a}$ & $1.7 \pm 0.2 \mathrm{a}$ & 11 \\
\hline 48 & $41.2 \pm 2.2 \mathrm{a}$ & $20.7 \pm 1.9 \mathrm{c}$ & 30 & - & - & \\
\hline 72 & $42.0 \pm 0.3 \mathrm{a}$ & $22.0 \pm 2.3 \mathrm{~cd}$ & 30 & - & - & \\
\hline 96 & $40.7 \pm 1.5 \mathrm{a}$ & $24.1 \pm 1.9 \mathrm{~cd}$ & 30 & - & - & \\
\hline
\end{tabular}
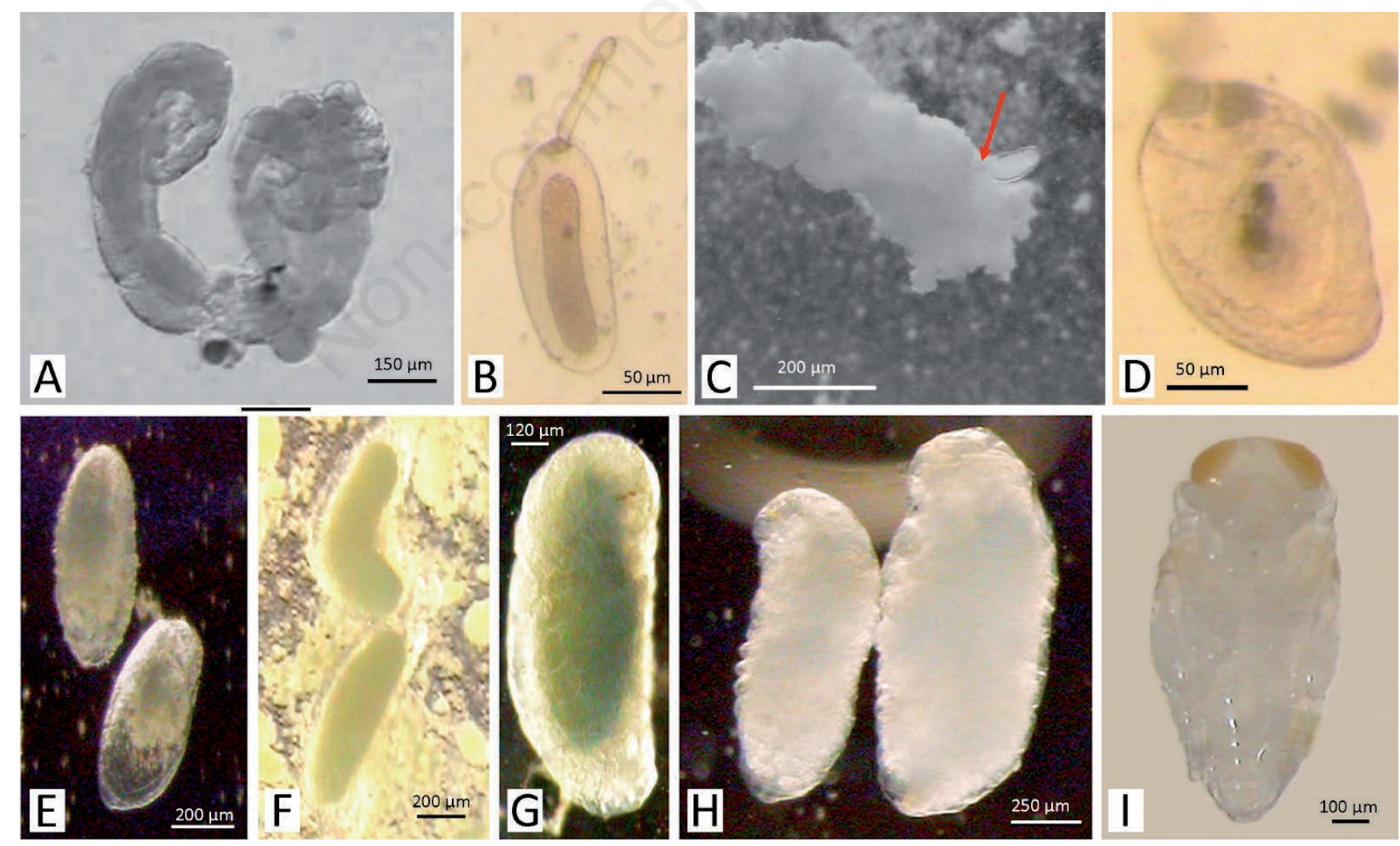

Figure 1. Ovarioles and immature stages of M. marensis. A. Ovarioles. B. Egg. C. Egg with stalked inserted in fat body (see arrow). D. First-instar larva. E. Second-instar larvae. F. Third-instar larvae. G. Fourth-instar larva. H. Prepupae. I. Pupa. 


\section{Second-instar larva}

The second-instar larva (Figure 1E) is elongate, each $514 \pm 129$ $\mu \mathrm{m}$ long and $231 \pm 18 \mu \mathrm{m}$ wide. This stadium lasted approximately 24 hours.

\section{Third-instar larva}

The third-instar larva (Figure 1F) is elongate each $636 \pm 147 \mu \mathrm{m}$ long and $239 \pm 36 \mu \mathrm{m}$ wide. The mandibles are amber in color and more sclerotized compared with the previous instars. This stadium lasted approximately 24 hours.

\section{Fourth-instar larva}

The fourth-instar larva (Figure 1G) is elongate, $949 \pm 181 \mu \mathrm{m}$ long, $446 \pm 88 \mu \mathrm{m}$ wide. This stadium lasted 2.5 to 3.0 days.

\section{Prepupa}

Once the parasitoid larva has consumed all the contents of the host, the integument of the parasitized eriococcid stays yellowish, but it turns brown in the following 24 hours. At this stage, the parasitized eriococcids are commonly referred to as "mummies". Along with the formation of cells, the parasitoid expels the meconium in the form of yellowish granules or "pellets". Immediately after, the parasitoid becomes a prepupa, which is whitish in color (Figure 1H). The prepupa is the final phase of the fourth instar, when the larva prepares to transform into a pupa. The prepupal stage lasts less than 24 hours.

\section{Pupa}

The pupa (Figure 1I) is of the exarate type; it is whitish during the first two days and then turns brown and finally bright black in color. The eyes are whitish during the first 24 hours, then change to

Table 2. Mandible length (Mandible-L) and head capsule width (HC-W) of Metaphycus marensis larval stages.

\begin{tabular}{llccc} 
Larval stage & N. & Nandible-L $(\mu m)$ & & HC-W ( $1 \mu m)$ \\
L1 & 35 & $7 \pm 1$ & 38 & $32 \pm 5$ \\
L2 & 36 & $16 \pm 3$ & 41 & $71 \pm 2$ \\
\hline L3 & 47 & $24 \pm 3$ & 43 & $182 \pm 4$ \\
L4 & 43 & $33 \pm 3$ & 43 & $234 \pm 3$ \\
\hline
\end{tabular}

$\mathrm{N}=$ number of measured individuals.

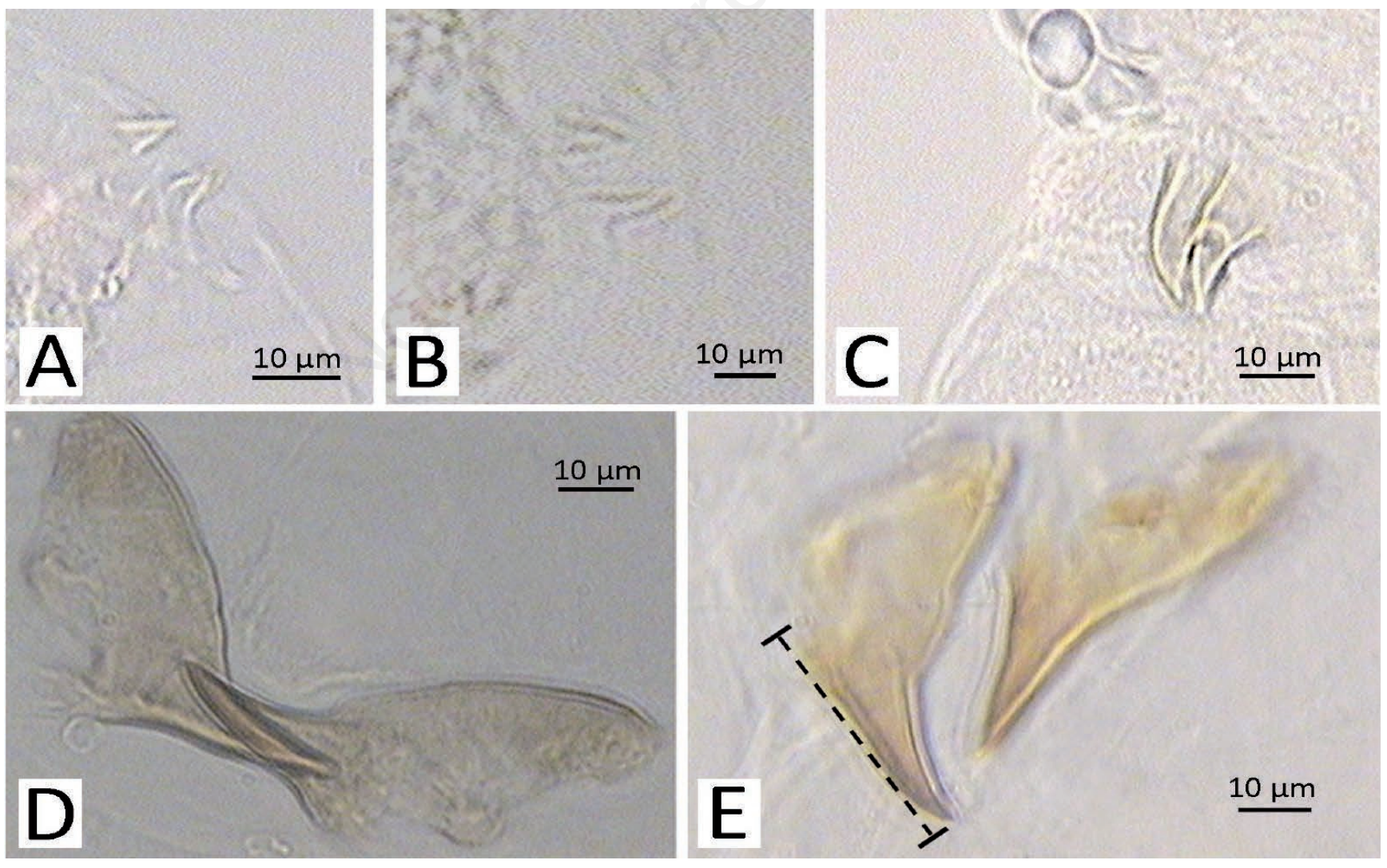

Figure 2. Mandibles of the larvae of Metaphycus sp. A. First-instar larva. B. Second-instar larva. C. Third-instar larva. D. Fourth-instar larva. E. Mandibles of the fourth-instar larva. 
amber and later turn brown after another 24 hours. The female pupa measures $1020 \pm 158 \mu \mathrm{m}$ long $\mathrm{x} 464 \pm 89 \mu \mathrm{m}$ wide and the male pupa $757 \pm 162 \mu \mathrm{m} \times 376 \pm 99 \mu \mathrm{m}$ wide.

No significant differences were found in the duration of the life cycle between female and male individuals $(\mathrm{P}<0.05)$ although the duration of the male lasted a little less in the pupal stage than that of the female parasitoid (Table 3). The duration of the life cycle of M. marensis ranged from 12 to 13 days.

\section{Parasitoid daily fecundity}

Figure 3 shows the distribution of the average oviposition of adult females of $M$. marensis throughout its lifetime. Although $M$. marensis is a sinovigenic species, the period of oviposition did not last beyond six days, most of the oviposition occurring from the second to the fourth day.

\section{Parasitoid survival $\left(\mathrm{l}_{\mathrm{x}}\right)$}

The mortality observed at the beginning of the life cycle (Figure 3) was mainly due to the encapsulation of eggs and first-instar larvae by the host. Subsequently, the mortality observed after 12 days corresponds to that of the adult stage. The survival curve of $M$. marensis is of type I, where the highest mortality (after encapsulation) occurred later in life.

\section{Population parameters}

For each generation that lasted 13.9 days $(T)$, the parasitoid multiplied its population by 28.7 times $\left(R_{o}\right)$ and the mean value for the intrinsic rate of natural increase $\left(r_{m}\right)$ was 0.242 female per day.

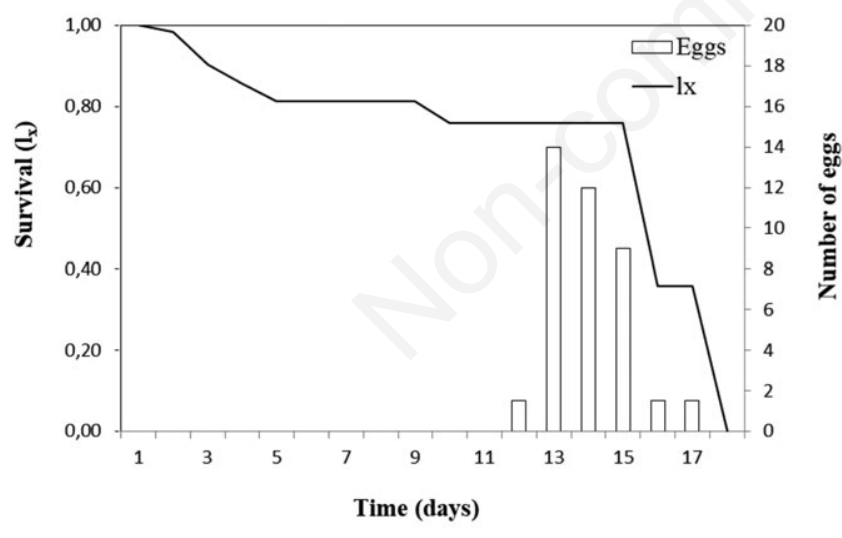

Figure 3. Survival $\left(\mathbf{l}_{\mathrm{x}}\right)$ and daily oviposition of Metaphycus marensis adult females on Capulinia linarosae.

\section{Discussion and Conclusions}

\section{Effect of feeding on oogenesis}

Metaphycus marensis is a synovigenic species and needs to feed on sources of carbohydrates to be able to complete the development of eggs within their ovarioles, as occurs with other species of this genus (Guerrieri \& Noyes, 2000; Kapranas \& Luck, 2008; Kapranas et al., 2010, 2011). Synovigenic parasitoid wasp species emerge with a small number of developed eggs and throughout their lifetime the rest of the eggs mature gradually (Gordh et al., 1999).

\section{Duration of the different stages and life cycle}

Within the Metaphycus genus, males generally emerge a little earlier than females, as reported previously (Kapranas et al., 2013; Kapranas \& Tena, 2015). For other species of Metaphycus, the duration of the life cycle is quite variable depending on the species, ranging from 13 to 35 days (Blumberg, 1997; Guerrieri \& Noyes, 2000; Stauffer, 2003). The life cycle of $C$. linarosae determined under the same laboratory conditions of this study lasts more than 22 days (Chirinos et al., 2004), which is longer than the duration of this parasitoid. A shorter development time of the parasitoid with respect to the host's development time is considered one of the attributes of an effective natural enemy since more generations of the parasitoid could occur and thus increase their populations more quickly (Debach, 1964).

\section{Parasitoid daily fecundity}

The oviposition period was shorter compared to other species within the same genus (Bernal et al., 1999; Guerrieri \& Noyes, 2000). This could have negative implications for the degree of biological control by $M$. marensis on $C$. linarosae. The most effective species for biological control are those that can live for a longer time because they can reproduce at low population densities of their insect host (Gordh et al., 1999).

However, low fertility is not always considered a limiting factor when deciding the efficiency of a parasitoid. Lane et al. (1999) pointed out that the low fecundity of a parasitoid should not be a limiting factor for its selection as a biological control agent, since other bio-ecological characteristics of the parasitoid as well as its host may influence the success of a biological control program. If the parasitoid has a shorter life cycle than its insect host, as in the case of $M$. marensis, the practical capability to regulate the populations of its host insect may be high, despite its comparatively low fecundity (Lane et al., 1999). As for host insects with sedentary habits, phytophages such as "hemipterans" are especially susceptible to parasitization because they are relatively easy to find due to the increase in the searching efficiency of the parasitoids, which compensates for deficiencies such as low fecundity. It is for this reason that biological control programs against phytophagous pests have had considerable success.

Table 3. Duration of the life cycle of $M$. marensis.

\begin{tabular}{cccccc} 
& N. & Egg & Larva & Pupa & Life cycle \\
우 & 883 & $1.6 \pm 0.2$ & $5.6 \pm 0.7$ & $5.7 \pm 0.5$ & $12.9 \pm 0.1 \mathrm{a}$ \\
o & 387 & $1.6 \pm 0.1$ & $5.6 \pm 0.2$ & $5.4 \pm 0$. & $12.5 \pm 0.1 \mathrm{a}$ \\
\hline
\end{tabular}

Means with the same letter within the same column do not differ significantly $(\mathrm{P}<0.05) . \mathrm{N}=$ number of individuals evaluated. 


\section{Parasitoid survival $\left(\mathbf{l}_{\mathbf{x}}\right)$}

Encapsulation of parasitoid eggs by Coccus hesperidum L. (Hemiptera: Coccidae) has been reported for several species of Metaphycus, e.g., Metaphycus luteolus Timberlake (Kapranas et al., 2009), M. flavus (Howard) (Tena et al., 2009; Kapranas et al., 2012) and M. angustifrons Compere (Kapranas et al., 2011).

\section{Population parameters}

Although the $R_{o}$ is considerably lower than that of its host (Ro: 1090), the $r_{m}(0.20)$ (Chirinos et al., 2004) was slightly lower, because of its short generation time. In addition, the efficiency of a parasitoid should be considered within the context of the insect-host-parasitoid relationship. The total oviposition rate of a female $M$. marensis is about 40 eggs, with an average of 2.2 eggs laid per host (Chirinos \& Kondo, 2019), thus a single parasitoid can parasitize up to 18 eriococcid hosts during its reproductive life.

The short generation time of $M$. marensis compared to that obtained for $C$. linarosae indicates that the development time of the parasitoid could be 3.2 times shorter, which can be considered as an attribute of a suitable natural enemy. However, the phenomenon of encapsulation by the host coupled with the relatively low longevity and fertility of the adult female parasitoid must be analyzed through field experiments in order to define its importance as a biological control agent. Since $M$. marensis is the only primary parasitoid associated with $C$. linarosae, this study which deals with the biological aspects of $M$. marensis constitute one of the first contributions for the understanding of the role of this primary parasitoid in the regulation of populations of $C$. linarosae, the major arthropod pest that affects the guava orchards in Venezuela and Colombia.

\section{References}

ANDERSON L.E. 1954 - Hoyer's solutions as a rapid permanent mounting medium for bryophytes. - The Bryologist 57: 242-244.

BERNAL J., ROBERT L.F., MORSE J.G. 1999 - Host influences on sex ratio, longevity and egg load of two Metaphycus species parasitic on soft scales: implications for insectary rearing. Entomol. Exp. Appl. 92(2): 191-204.

CHIRINOS D.T., GERAUD-POUEY F., ROMAY G. 2004 Development and reproduction of Capulinia n. sp. close to jaboticabae von Ihering (Hemiptera: Eriococcidae) on guava. Entomotropica 19(3): 135-142.

CHIRINOS D.T., KONDO T. 2019 - Description and Biological Studies of a New Species of Metaphycus Mercet, 1917 (Hymenoptera: Encyrtidae), A Parasitoid of Capulinia linarosae Kondo \& Gullan. - Int. J. Insect Sci. 11: 1-9.

CHIRINOS D.T., ROMAY G., FERNÁNDEZ C.E., CASTRO R. 2017 - Capulinia linarosae Kondo and Gullan, 2016: History and current situation as a guava pest, Psidium guajava L. in Venezuela. - Rev. Fac. Agron. Luz. 34(4): 397-427.

CLAUSEN C.P. 1940 - Entomophagous insects. New York, USA: McGraw-Hill. Edit. 688 pp.

DEBACH P. 1964 - Biological Control of Insects Pests and Weeds. New York, USA: Reinhold Publisher Co.: 884 pp.

GARCÍA MORALES M., DENNO B., MILLER D.R., MILLER G.L., BEN-DOV Y., HARDY N.B. 2019 - ScaleNet: A literature-based model of scale insect biology and systematics. Database. Available from . Accessed: 16 march, 2020.

GORDH G., LEGNER E.F., CALTAGIRONE L. 1999 - Biology of parasitic Hymenoptera. p. 355-381. In: Fisher T, Bellows TS,
Caltagirone L, Dahlsten D, Huffaker C, Gordh G, eds. Handbook of Biological Control. California, USA: Academy Press: 1046 pp.

GUERRIERI E., NOYES J. 2000 - Revision of European species of genus Metaphycus Mercet (Hymenoptera: Encyrtidae) parasitoids of scale insects (Homoptera: Coccoidea). - Syst. Entomol. 25(2): 147-222.

GULLAN P.J., COOK L.G. 2007 - Phylogeny and higher classification of the scale insects (Hemiptera: Sternorrhyncha: Coccoidea). - Zootaxa 1668: 413-425.

HODGSON C., ISAIAS R. M. S. \& OLIVEIRA D. C. 2013 - A new gall-inducing genus and species of Eriococcidae (Hemiptera: Sternorrhyncha: Coccoidea) on Sapindaceae from Brazil. - Zootaxa. 3734: 317-330.

KAPRANAS A., FEDERICI B.A., LUCK R.F., JOHNSON, R.F. 2009 - Cellular immune response of brown soft scale Coccus hesperidum L. (Hemiptera: Coccidae) to eggs of Metaphycus luteolus Timberlake (Hymenoptera: Encyrtidae). - Biol. Control 48(1): 1-5.

KAPRANAS A., HARDY I.C.W., LUCK R.F., MORSE, J.G. 2011 - Parasitoid developmental mortality in the field: patterns, causes and consequences for sex ratio and virginity. - J. Anim. Ecol. 80(1): 192-203.

KAPRANAS A., LO GIUDICE D., LUCK R.F., MORSE, J.G. 2010 - Biology and behavior of Metaphycus angustifrons Compere (Hymenoptera: Encyrtidae), a newly discovered parasitoid of soft scale insects (Hemiptera: Coccidae) in California. - Biol. Control 56(2): 139-144.

KAPRANAS A., LO GIUDICE D., PERI E., MILlAR J.G., COLAZZA, S. 2013 - Emergence, dispersal, and mate finding via a substrate-borne sex pheromone in the parasitoid Metaphycus luteolus (Hymenoptera: Encyrtidae). - Entomol. Exp. Appl. 148(1): 74-83.

KAPRANAS A., LUCK R.F. 2008 - Egg maturation, host feeding, and longevity in two Metaphycus parasitoids of soft scale insects. - Biol. Control 47(2): 147-153.

KAPRANAS A., PACHECO P., FORSTER L.D., MORSE J.G., LUCK R.F. 2008 - Precise sex ratios manifested by several encyrtid parasitoids (Hymenoptera: Encyrtidae) of brown soft scale, Coccus hesperidum L. (Hemiptera: Coccidae). - Behav. Ecol. Sociobiol. 62(6): 901-912.

KAPRANAS A., TENA A., LUCK R.F. 2012 - Dynamic virulence in a parasitoid wasp: the influence of clutch size and sequential oviposition on egg encapsulation. - Anim. Behav. 83: 833-838.

KAPRANAS A., TENA, A. 2015 - Encyrtid parasitoids of soft scale insects: biology, behavior, and their use in biological control. Annu. Rev. Entomol. 60: 195-211.

KONDO T., GULLAN P.J., COOK L.G. 2016 - A review of de genus Capulinia Signoret (Hemiptera: Coccoidea: Eriococcidae) with description of the two new species. Zootaxa 4111: 471-491.

KREBS, C. 1978 - Ecology: The Experimental Analysis of Distribution and Abundance. New York, USA: Harper and Row: 678 pp.

LANE S.D., MILLS N.J., GETZ W.M. 1999 - The effects of parasitoids fecundity and host taxon on the biological control of insect pest: the relationship between theory and data. - Ecol. Entomol. 24(2): 181-190.

MANSOUR R., GRISSA-LEBDI K., SUMA P., MAZZEO G., RUSSO A. 2017 - Key scale insects (Hemiptera: Coccoidea) of high economic importance in a Mediterranean area: host plants, bio-ecological characteristics, natural enemies and pest management strategies - a review. - Plant Protect. Sci. 53: 1-14. MILLER D.R. 2005 - Selected scale insect groups (Hemiptera: 
Coccoidea) in the southern region of the United States. - Fla. Entomol. 88: 482-501.

MILLER D.R., MILLER G.L., WATSON G.W. 2002 - Invasive species of mealybugs (Hemiptera: Pseudococcidae) and their threat to U.S. Agriculture. - Proc. Entomol. Soc. Wash. 104: 825-836.

SAS INSTITUTE INC. 2009 - SAS statistical program for microcomputers. Version 6.12, U.S.A.

STAUFFER S. 2003 - Metaphycus alberti Hymenoptera: Encyrtidae. https://biocontrol.entomology.cornell.edu/para sitoids/metaphycus.php
TENA A., KAPRANAS A., GARCIA-MARI F., LUCK R.F. 2009 - Larval cannibalism during the late developmental stages of a facultatively gregarious encyrtid endoparasitoid. - Ecol. Entomol. 34(6): 669-676.

YAM TZEC A., VILLASEÑOR PEREA J., ROMANTCHIK KRIUCHKOVA C.A., SOTO ESCOBAR MARTÍN, E., PEÑA PERALTA M.A. 2010 - A review about guava (Psidium guajava L.) fruit importance and their main ones characteristic in the postharvest. - Rev. Cienc. Téc. Agropecu. 19(4): 74-82. 